\section{Identification of key career indicators in Portuguese football players}

\author{
Ricardo Monteiro', Diogo Monteiro ${ }^{2,3}$, Célia Nunes ${ }^{4}$, \\ Miquel Torregrossa ${ }^{5}$ and Bruno Travassos ${ }^{1,3,6}$ (D)
}

International Journal of Sports Science \& Coaching $0(0) 1-9$

(C) The Author(s) 2020 Article reuse guidelines: sagepub.com/journals-permissions DOl: $10.1177 / 1747954120923198$ journals.sagepub.com/home/spo (\$)SAGE

\begin{abstract}
The aim of this study was to describe and identify the weight of some key career indicators $(\mathrm{KCl})$ on the competitive level of retirement (professional vs. non-professional) of Portuguese football players. Three thousand five hundred retired Portuguese football players born between 1950 and 1989, and registered on Portuguese Football Federation were considered in this study. Descriptive analysis and a multivariable binary logistic regression model were performed to assess the relationship between the mastery stage development variables and the competitive level of retirement of football players. The results highlighted that the $\mathrm{KCl}$ first senior registration level, number of seasons in mastery stage, number of total games as senior player, number of total games in retirement season, and the age of the last best result achieved contribute to explain and predict the competitive level of retirement of Portuguese football players. The tendencies identified and their impact on the competitive level of retirement could be important implications on awareness and definition of management and support programs of players' careers.
\end{abstract}

\title{
Keywords
}

Career management, career retirement, football players, holistic athletic career model

\section{Introduction}

In the sports context, athletic retirement has been one of the most popular topics of career transitions research worldwide. ${ }^{1,2}$ The purpose is to identify and evaluate the best predictors that explain the athletic retirement and the quality of athletic retirement in different sports see Park et al. ${ }^{3}$ for a review. However, in football and in general in team sports, the analysis of career development and athletic retirement is far from being a hot topic of research. ${ }^{4,5}$ Despite the well-known and reported problems that football players faced at the end of their athletic career, ${ }^{6-8}$ a recent systematic review on athletic retirement in football only reported eight studies in last 18 years ${ }^{5}$ and despite some similarities between studies, it was highlighted that the motives of retirement are dependent on the country in analysis. ${ }^{5,9}$

Interestingly, the common factor of retirement between all the countries and one of the most reported was age. Similar results were obtained in other sports, with the age of retirement being one of the factors that most influence the athletic retirement. ${ }^{1,3,10,11}$ It was well reported that elite athletes and, in particular, football players try to maintain their athletic activity as long as possible delaying the moment of retirement. This issue is also related to the high athletic identity and the lack of career planning reported by almost all elite athletes ${ }^{4,11,12}$ and, in particular, elite football players in Portugal. ${ }^{9}$ Indeed, the behavior of elite football players to delay the moment of retirement could be

\section{Reviewer: $\mathbf{~ [ A Q 2 ] ~}$}

'Department of Sport Sciences, Universidade da Beira Interior, Covilhã, Portugal

${ }^{2}$ Escola Superior de Desporto de Rio Maior (ESDRM-IPSantarém), Rio Maior, Portugal

${ }^{3}$ CIDESD, Centro de Investigação em Desporto, Saúde e Desenvolvimento Humano, CreativeLab, Vila-Real, Portugal ${ }^{4}$ Department of Mathematics and Center of Mathematics and Applications, Universidade da Beira Interior, Covilhã, Portugal ${ }^{5}$ Universitat Autónoma de Barcelona, Barcelona, Spain [AQ1] ${ }^{6}$ Portugal Football Scholl, Portuguese Football Association, FPF, Portugal

\section{Corresponding author:}

Bruno Travassos, Department of Sport Sciences, University of Beira Interior (UBI), Convento de Sto. António, 6200-00I Covilhã, Portugal. Email: bruno.travassos@ubi.pt 
related to the lack of consciousness about the future and with the immediate perspective to maintain the financial support and social status. ${ }^{12,13}$ However, the lack of consciousness about career planning and the delay in retirement could contribute to difficulties in adaptation to a new life, including negative emotional and social reactions. ${ }^{1,12,14}$ Furthermore, the delay in retirement also influences/influenced the capability of players to/or not to maintain the professional status and the level at the end of their career with consequences on the expectations of players about the future and the acceptance of the retirement process. ${ }^{1,12,14}$ Thus, there is a need to better understand the retirement process and to improve the analysis of the athletic career path of players. In agreement with the Holistic Athletic Career Model, there is a need to better understand what characterizes each athletic stage and how it influences the retirement process.

\section{The Holistic Athletic Career Model}

In last years, the Holistic Athletic Career Model ${ }^{15}$ was suggested as a more adequate approach to understand the athletic retirement as part of a process of players' development. Over their entire career, the changes that athletes' experience afford several individual challenges, such as complex emotions, negotiation of changes in their identity, as well as, the disruption of their social network. ${ }^{16}$ This model considers that an athletic career is defined by different stages of development that integrate other life domains. ${ }^{10}$ Four main stages (initiation, development, mastery and discontinuation), and six normative athletic transitions (the beginning of sports specialization, start of intense training in a sport, high achievement, and adult sports, beginning of professional sports, peak performance to the end of a sports career and the end of athletic career) were identified as part of the development of the athletic career. ${ }^{4,17}$

\section{Stages of football players' career development}

Looking at initiation and development stages, recent research revealed that the career paths in German youth national teams are characterized by eight different career paths. ${ }^{18}$ Each path is characterized by specific relations across different variables, namely: the number of years as youth players, the appearances in the national teams, or being or not professional. A recent retrospective study with Portuguese international football players also revealed that over the last 10 years, the career path started earlier with an increase in the length of initiation and development stages (increase in the number of years as youth players) and a decrease in the length of the mastery stage (decrease in the number of years as professional players). ${ }^{19}$

Regarding the mastery stage, in handball ${ }^{20}$ and in NHL, ${ }^{21}$ it was highlighted that the mastery stage is characterized by four major career stages related to the level of performance of practice (i.e. access to semi-professional or professional sport, developing as a professional player, reaching the elite, and maintaining the professional status). Both studies reinforce that the mastery stage lies between the normative transitions from junior to senior and retirement and integrates different non-normative transitions that players face during their senior career. ${ }^{20}$ During all the stages, and particularly in the mastery stage, the athletic path is nonlinear and subtle changes in the career development could potentiate unexpected career paths. ${ }^{18}$ Likewise, it was stated that career pathways were not consciously defined along with the career ${ }^{12}$ and did not consider a previous plan of development, in line with the reported in football. ${ }^{9}$

Previous research highlighted the relationship between career plan, career self-efficacy and career goals as a process to improve the retirement process. ${ }^{12}$ However, to the best of our knowledge no study exists in football that characterizes and identifies some key career indicators $(\mathrm{KCI})$ that help players to consciously manage their choices to potentiate the mastery stage and the time of career termination. In line with previous research, ${ }^{18}$ the identification of the relevant $\mathrm{KCI}$ such as the age and competitive level at the moment of promotion to senior player, the number of seasons and total of games as senior player, the age of peak performance, and the number of games in retirement season are paramount to consciously explain the path of career development and retirement. Further research is required to understand the weight of each $\mathrm{KCI}$ on career development and retirement of football players.

Thus, the purpose of this study was to describe and identify the weight of the KCI from the mastery stage on the competitive level of retirement (professional vs. non-professional) of Portuguese football players. It was our expectation to identify some KCIs that help to predict the competitive level of retirement of Portuguese football players. Such results will be of major importance for the future definition of management and support programs of players' careers.

\section{Method}

\section{Participants}

Public data about the sport career path of three thousand five hundred $(n=3500)$ retired Portuguese football players born between 1950 and 1989, registered on Portuguese Football Federation and on a private 
digital website platform (www.zerozero.pt) were considered for analysis.

\section{Data collection}

The tracking of the mastery stage of each player was followed since the age of the first registration as senior player until the end of the career. The data to identify Portuguese football players' career were collected with the support of zerozero website platform. Five percent of the data were subjected to a comparison with data from the Portuguese Football Federation about players' careers using Cohen's Kappa index $(k) .{ }^{22}$ The results revealed a very good agreement between data $(k=0.97)$.

\section{Data analysis}

The data from the athletic career of Portuguese football players (see Table 1) were categorized according to the KCI defined for mastery stage of the athletic career. ${ }^{15} \mathrm{KCI}$ from the mastery stage were identified as independent variables while the level of competitive retirement was identified as the dependent variable.

Subsequently, a descriptive analysis of the $\mathrm{KCI}$ according to the competitive level of retirement (professional or non-professional) and a multivariable binary logistic regression model were performed to assess the relationship between the KCI from the mastery stage (age at first registration as senior player, the age of the last best result achieved, total number of games as senior player, number of games in retirement season, number of seasons as senior player, first senior competitive level, retiring age, and the competitive level of retirement of football players. The competitive level of retirement was defined according to the possible competitive levels achieved by Portuguese players: (a) Professional players - (1) Elite - players that reached the national team as senior players; (2) 1st Pro - players that reached the 1st league in Portugal; (3) 2nd Pro players that reached the 2nd league in Portugal; and (b) Non-professional players - (4) Non Pro - players that played in nonprofessional divisions in Portugal.

Only the variables whose univariate test was significant $(p<.05)$ were selected to the model. The nominal KCI were analyzed through the chi-square test and the continuous variables by the Mann-Whitney $U$ test (since the assumptions underlying the use of the independent samples $t$-test were not verified) with the correspondent effect sizes (Eta squared, $\eta^{2}$ ). ${ }^{23}$ The interpretation of the effect size using $\eta^{2}$ was based on the following criteria ${ }^{24}:<.01$ no effect, $0.01-0.04$ small effect, 0.06-0.11 intermediate effect and $0.14-0.20$ large effect.

The forward stepwise (likelihood ratio) selection method was considered and the results were reported by odds ratio (OR) estimates and their $95 \%$ confidence intervals (CI). To evaluate the model's power of explanation the Nagelkerke's $R^{2}$ was used. Its interpretation as an effect size measure was made based on the following criteria: 0.02-0.13 small, 0.13-0.26 medium, and $>0.26$ large effect size. ${ }^{25}$ The model's goodness of fit

Table I. Description of the key career indicators of the mastery stage of Portuguese football players.

\begin{tabular}{|c|c|c|c|}
\hline Stage & Variable & & Description \\
\hline \multirow[t]{7}{*}{ Mastery } & $\begin{array}{l}\text { Age of first registration as } \\
\text { senior player }\end{array}$ & AFRSP & $\begin{array}{l}\text { Were considered the age that an athlete starts to play in seniors. It } \\
\text { allows to identify the age of transition from junior to senior }\end{array}$ \\
\hline & First senior competitive level & FSCL & $\begin{array}{l}\text { Were considered the competitive level in which an athlete starts to play } \\
\text { in seniors. It allows to identify the competitive level at the moment of } \\
\text { transition from junior to senior: } \\
\text { - elite (players who achieved national team); } \\
\text { - first professional level (achieved the first national league); } \\
\text { - second professional level (achieved the second national league); and } \\
\text { - non-professional level }\end{array}$ \\
\hline & $\begin{array}{l}\text { Number of seasons as senior } \\
\text { player }\end{array}$ & NSSP & $\begin{array}{l}\text { Were considered the total number of seasons that a football player } \\
\text { played as senior }\end{array}$ \\
\hline & $\begin{array}{l}\text { Total number of games as } \\
\text { senior player }\end{array}$ & NTGSP & $\begin{array}{l}\text { Were considered the total number of games that a football player played } \\
\text { as senior }\end{array}$ \\
\hline & $\begin{array}{l}\text { Number of games in retire- } \\
\text { ment season }\end{array}$ & NGRS & $\begin{array}{l}\text { Were considered the total number of games that a football player played } \\
\text { in the retirement season }\end{array}$ \\
\hline & $\begin{array}{l}\text { The age of the last best result } \\
\text { achieved }\end{array}$ & LBRAA & $\begin{array}{l}\text { Were considered the players' age at the time of the last season at the } \\
\text { peak performance (higher competitive level achieved) }\end{array}$ \\
\hline & Retiring age & RA & $\begin{array}{l}\text { Were considered the age at the time a football player ends his sports } \\
\text { career }\end{array}$ \\
\hline Retirement & Retirement competitive level & $\mathrm{RCL}$ & $\begin{array}{l}\text { Were determined two competitive levels in the retirement season: }(I) \\
\text { professional level and (2) non-professional level }\end{array}$ \\
\hline
\end{tabular}


was assessed through the Hosmer-Lemeshow test and the area under the curve (AUC) through receiver operating characteristic (ROC) was used to evaluate the discriminant capacity of the model. The ROC curve was performed using the predicted probabilities of each variable. All the statistical analyses were performed using SPSS 24.0 and statistical significance for rejecting the null hypothesis was set at $p<.05$.

\section{Results}

\section{Characterization of mastery stage}

The age of first registration as senior of Portuguese football players is around 18 years old $(M=17.94$, $S D=0.69)$ and the number of seasons as senior players is around 14 years $(M=14.08, S D=4.36)$. During their entire career, Portuguese football players played, on average, around 93 games $(M=92.96, S D=125.69)$ and only three games in the retirement season $(M=3.37, S D=7.49)$. The age of the last best result achieved was at around 27 years old $(M=26.8$, $S D=5.07)$. Usually, the age of retirement is around 33 years $(M=32.70, S D=4.27$; see Table 2$)$.

How does mastery stage influences the competitive level of retirement of football players (professional or non-professional)?

Results revealed significant differences for all KCI $(p<.05)$ with exception to the age at first registration as senior player $(p=.06)$ and retiring age $(p=.97)$ between professional and the non-professional level at the moment of retirement. In addition, effect size results also revealed no effect for the number of seasons as senior player (see Table 2).

The analysis of the relationship between the first senior competitive level and the last competitive level achieved by the football players revealed a significant result $(p<.001)$ (see Table 3$)$. The first competitive level as senior player influences the competitive level of the retirement of players. Considering the four competitive levels at the moment of retirement, $20 \%$ of players who enter in mastery stage as elite players, $69.4 \%$ as first pro players, and $74.1 \%$ as second pro players, finish their career as non-professional players. Also, $92.3 \%$ of the players that enter in mastery stage as non-professional finished their career as nonprofessional players.

In the multivariable binary logistic regression model, the independent variables age at first registration as senior player and retiring age were excluded from the model $(p=.06)$. The overall model presents a wellfitting value $\left(\mathrm{p}_{\text {Hosmer-Lemeshow }}>.05\right)$, a good correct global classification $(90.5 \%)$ and its discriminant capacity is also quite good with the AUC ranging between .905 - .949. The model accounts for 51.1\% of the explanation for the competitive level of retirement (Negelkerke $R^{2}=0.512$ ), corresponding to a large effect size (see Table 4).

The results revealed that for each additional season played in the mastery stage, the chances of finishing their career as a professional player decreased by $26.9 \% \quad\left(O R=0.731, \quad I C_{95 \%}=[0.695-0.768]\right) . \quad$ The

Table 2. Descriptive data of the key career indicators from the mastery stage according with the retirement competitive level (professional or non-professional).

\begin{tabular}{|c|c|c|c|c|c|}
\hline & \multirow[b]{2}{*}{$\begin{array}{l}\text { Total } \\
n=3467 \\
\text { Md (IR) }\end{array}$} & \multicolumn{2}{|c|}{$\begin{array}{l}\text { Competitive level of } \\
\text { retirement dichotomic }\end{array}$} & \multirow[b]{2}{*}{ p-value\#I } & \multirow[b]{2}{*}{$\eta^{2}$} \\
\hline & & $\begin{array}{l}\text { Professional } \\
n=499 \\
\text { Md (IR) }\end{array}$ & $\begin{array}{l}\text { Non-Pro } \\
n=2968 \\
\text { Md (IR) }\end{array}$ & & \\
\hline Age at first registration as senior player & $18(0)$ & $18(0)$ & $18(0)$ & .06 & $\begin{array}{l}0.00 \\
\text { (no effect) }\end{array}$ \\
\hline Number of seasons as senior player & $15(6)$ & $15(4)$ & $14(6)$ & .01 & $\begin{array}{l}0.00 \\
\text { (no effect) }\end{array}$ \\
\hline Total number of games as a senior player & $33(134)$ & $234(225)$ & $24(85)$ & $<.001$ & $\begin{array}{l}0.21 \\
\text { (large effect) }\end{array}$ \\
\hline Number of games in retirement season & $0(2)$ & $9(16)$ & $0(0)$ & $<.001$ & $\begin{array}{l}0.15 \\
\text { (large effect) }\end{array}$ \\
\hline The age of the last best result achieved & $27(8)$ & $31(6)$ & $26(8)$ & $<.001$ & $\begin{array}{l}0.07 \\
\text { (intermediate effect) }\end{array}$ \\
\hline Retiring age & $33(6)$ & $33(4)$ & $33(6)$ & 0.97 & $\begin{array}{l}0.00 \\
\text { (no effect) }\end{array}$ \\
\hline
\end{tabular}

Note: \#I Mann Whitney test. [AQ4]

Md: median; IR: interquartile range. 
Table 3. Relationship between competitive level of retirement (dichotomic) and first senior competitive level.

\begin{tabular}{lcccc}
\hline \multicolumn{5}{c}{ Competitive level of retirement (dichotomic) } \\
\cline { 2 - 5 } & \multicolumn{1}{l}{ Total } & Professional & Non-Pro \\
$n=3467(100 \%)$ & $n=499(14.4)$ & $n=2968(85.6)$ & [AQ5] pvalue 2 \\
\hline First senior competitive level & $5(0.1)$ & $4(80.0)$ & $1(20.0)$ & $<.00$ I \\
Elite & $592(17.1)$ & $181(30.6)$ & $4 I I(69.4)$ & \\
Ist Pro & $510(14.7)$ & $132(25.9)$ & $378(74.1)$ & \\
2rd Pro & $2360(68.1)$ & $182(7.7)$ & $2178(92.3)$ & \\
Non-Pro & & &
\end{tabular}

Note: \#2: Chi-Square test (Pearson Chi-square).

Table 4. Estimated regression coefficients from binary logistic regression analysis, only for significant variables (competitive level of retirement as dependent variable).

\begin{tabular}{|c|c|c|c|c|}
\hline Variables & $B$ & OR (Cl 95\%) & $\mathrm{P}$ & $\mathrm{AUC}(\mathrm{Cl} 95 \%)$ \\
\hline The age of the last best result achieved & 0.185 & $1.203(1.156-1.252)$ & $<.001$ & $.949(.94 I-.957)$ \\
\hline Number of seasons as senior player & -0.314 & $0.731(0.695-0.768)$ & $<.001$ & $.905(.891-.920)$ \\
\hline Total number of games as a senior player & 0.010 & $1.010(1.008-1.011)$ & $<.001$ & $.949(.94 I-.957)$ \\
\hline Number of games in retirement season & 0.066 & $1.068(1.053-1.083)$ & $<.001$ & $.905(.891-.920)$ \\
\hline \multicolumn{5}{|l|}{ First senior registration level } \\
\hline Non-Pro ${ }^{\mathrm{a}}$ & & I & & \\
\hline Elite & $1.53 \mathrm{I}$ & $4.624(0.382-55.958)$ & .23 & $.942(.932-.95 \mathrm{I})$ \\
\hline Ist & 1.257 & $3.516(2.531-4.885)$ & $<.001$ & $.949(.94 I-.957)$ \\
\hline 2nd & 1.043 & $2.839(2.042-3.946)$ & $<.001$ & $.905(.891-.920)$ \\
\hline Nagelkerke $\mathrm{R}^{2}=0.5 \mathrm{II}$ & \multicolumn{2}{|c|}{ Hosmer-Lemeshow test $(p=.3 \mid 2)$} & \multicolumn{2}{|c|}{ Correct global classification $=90.5 \%$} \\
\hline
\end{tabular}

OR: odds ratio; AUC: area under the ROC curve.

${ }^{a}$ Reference category.

analysis of the total number of games as senior player revealed that for each additional game played during the master stage, the chance to finish the career as a professional player increases by $1 \%(O R=1.010, I C 95 \%=$ [1.008-1.011]). Interestingly, for each additional game played during the retirement season, the chance to finish the career as a professional player increases by $6.8 \%(O R=1.068, I C 95 \%=[1.053-1.083])($ see Table 4$)$.

Regarding the age of the last best result achieved, a player who ensured one year more has 20.3\% more chance to finish the career as professional when compared with a player who ensured "the age of the last best result achieved" one year earlier $(O R=1.203$, $\left.I C_{95 \%}=[1.156-1.252]\right)($ see Table 4).

At the end, the analysis of the relationship between the first senior registration level and the competitive level of retirement revealed that a player who starts the Mastery stage in the elite level has 4.6 times more chances to finish his career as a professional when compared with a player who starts as a non-professional $\left(O R=4.624, \quad I C_{95 \%}=[0.382-55.958]\right)$. A player who starts in the first pro level has $3.5(O R=3.516$, $\left.I C_{95 \%}=[2.531-4.885]\right)$ more chances to finish his career as a professional when compared with a player who starts as a non-professional, while a player who starts in the second pro level has $2.8(O R=2.839$, $\left.I C_{95 \%}=[2.042-3.946]\right)$ more chances to finish his career as a professional when compared with a player who starts as a non-professional (see Table 4).

In order to improve the understanding of previous results, some case studies of players' career development and termination are presented in Table 5. For example, player $1(\mathrm{P} 1)$ and player $2(\mathrm{P} 2)$ maintain a high level of practice (participation in the national team) until the end of their career. However, while in his last season P1 only performed two games, P2 maintained a regular practice with 45 games played in his retirement season. However, both have decided to retire as professional players in highly competitive level. While the results of $\mathrm{P} 1$ are completely in agreement with the presented model, P2 is a little bit different due to the decision to retire from the competition even with a high number of games in the retirement season. In opposition, player $3(\mathrm{P} 3)$, player $4(\mathrm{P} 4)$ and player 5 (P5) achieved their peak performance (higher competitive level achieved) at a young age, and due to a transference to other clubs in Portugal or in another country could not maintain the same 
Table 5. Case studies of players' career development and termination.

\begin{tabular}{lllllll}
\hline Player & $\begin{array}{l}\text { First competitive } \\
\text { level }\end{array}$ & $\begin{array}{l}\text { Number of } \\
\text { seasons as senior }\end{array}$ & $\begin{array}{l}\text { The age of the last best } \\
\text { result achieved }\end{array}$ & $\begin{array}{l}\text { Number of games in } \\
\text { retirement season }\end{array}$ & $\begin{array}{l}\text { Age of } \\
\text { retirement }\end{array}$ & $\begin{array}{l}\text { Competitive level } \\
\text { of retirement }\end{array}$ \\
\hline PI & Professional & 20 & 37 years & 2 & 38 years & Professional \\
P2 & Non-professional & 18 & 36 years & 45 & 36 years & Professional \\
P3 & Professional & 21 & 25 years & 7 & 40 years & Non-professional \\
P4 & Professional & 17 & 31 years & 12 & 35 years & Non-professional \\
P5 & Professional & 14 & 22 years & 38 & 29 years & Non-professional \\
\hline
\end{tabular}

level of performance or even achieve again the same high level of performance. In line with the proposed model, the sooner the high level was achieved without the maintenance of performance in subsequent years, the higher the chance to finish the career as a nonprofessional. Both of P3, P4, and P5 ended their career as non-professionals unlike P1 and P2. Interestingly, despite ending the career in younger ages and in a non-professional competitive level, P3 and $\mathrm{P} 4$ also performed a low number of games in retirement season even in non-professional levels. The number of games of P5 in retirement season was high but in a non-professional team.

\section{Discussion}

Following previous research of career retirement of Portuguese football players, ${ }^{9}$ and considering the Holistic Athletic Career Model, ${ }^{15}$ the aim of this study was to describe and identify the weight of the KCI of the mastery stage of Portuguese football players on the competitive level of retirement (professional vs. non-professional). Based on our expectations, it was clear that the KCI first senior registration level, number of seasons in mastery stage, number of total games as senior player, number of total games in retirement season, and the age of the last best result achieved, contribute to explain and predict the competitive level of retirement of Portuguese football players. Alfermann and Stambulova ${ }^{26}$ described the successful retirement as a positive state that promotes an easy transition out of the sport, thanks to the effective mobilization of the resources to promote a voluntary retirement. The monitoring and analysis of such KCI over the entire career could improve the consciousness of players and managers about how to prospectively manage their careers and prospectively prepare the moment of retirement successfully. ${ }^{12}$

\section{Characterization of the mastery stage}

In general, the Portuguese football players start the mastery stage at around 18 years old without a significant difference between groups. This result is clearly influenced by the guidelines of football competitions and in line with previous research both in football ${ }^{18}$ and handball. ${ }^{4}$

During their entire career, Portuguese football players played, on average, 93 games and only three games in the retirement season. That is, the evolution of the number of games played in each season or the deselection trend could help players and managers to understand the evolution of their career and the intention of players to prepare their retirement. ${ }^{13}$ Deselection is one of the motives most reported in involuntary retirement by Portuguese football players ${ }^{9}$ with the associated difficulties in adaptation to termination, including negative emotional reactions as well as difficulty with accepting one's new life. ${ }^{1,14}$ Football players that retired by deselection were faced with the difficult decision to terminate their sporting careers pre-maturely and to start another professional career. ${ }^{27}$ More bench time athletes were words used by Butt and Molnar $^{28}$ to characterize these athletes. Therefore, the control of the athlete's decision to drop out the practice of sport seems to be associated with uncontrollable causes (e.g., deselection), which may lead to permanent dropout. $^{28}$ Thus, the idea of looking to these variables with further attention is to transform possible uncontrollable variables and decisions in more controlled and conscious ones or at least variables that need to be attended by the players over their career. ${ }^{12}$ In this regard, the managers and players need to know how to look to the tendencies of career development during the mastery stage to prepare the career termination and consequently their new career out of sports. Actually, it is a hot topic in sports and in society right now. Stambulova and Wylleman ${ }^{29}$ refereed that career planning interventions are fundamental to assist athletes to increase self-awareness, to define realistic career goals and prepare the forthcoming career steps and transitions.

The participants in our study revealed a lower number of seasons in mastery stage than the Brazilian players, $^{30}$ or the elite Portuguese football players. $^{9}$ However, the study of Carapinheira, Torregrossa ${ }^{9}$ only considered 90 Portuguese elite players and in this study, it was considered a very large sample of players from different levels. Also, the same authors 
revealed that, for elite football players, the mean number of seasons in the mastery stage has decreased in the last three decades, approaching our results. It looks to be a downward trend in the length of the mastery stage in Portuguese football.

In general, Portuguese football players achieved their last best result around 27 and finish their careers at around 33 years old. Interestingly, the age of career termination was not influenced by the competitive level of retirement. Regarding the age of the last best result achieved (peak performance age), previous researches in football revealed an age of around $25^{31}$ and between the ages $25-27$ years old, ${ }^{32}$ while in track and field peak performance was achieved at around 25 to 26 years old. However, further research is required in order to really identify trends in the age of the last best result achieved in different sports and according to reliable criteria. ${ }^{33}$ Our sample of Portuguese football players retired with a similar age of Kenyan and English footballers, ${ }^{34,35}$ earlier than Brazilian footballers/basketball players, ${ }^{30}$ but later than other Greek and Spanish elite athletes in different Olympic sports, ${ }^{11}$ and the football players in the four major European professional football leagues. ${ }^{32}$ The results seem to be in line with the previous research of Carapinheira, Mendes ${ }^{19}$ that revealed that the retiring age of Portuguese football players has decreased in the last three decades from 36 to 34 years old. This decrease in the age of retirement cannot be considered positive or negative, because it does not influence the competitive level of retirement. However, according to the Portuguese football players, age is one of the main variables for involuntary retirement. ${ }^{9}$ With the decrease in the age of retirement, the time to accept the retirement and the time to prepare and develop a new career also decreases. Thus, it could contribute to difficulties in adaptation to termination, including dissatisfaction with the sudden change and negative emotional reactions to it, as well as difficulty with accepting one's new life. ${ }^{1,14}$

\section{How does the mastery stage influences the competitive level of retirement of football players (professional or non-professional)?}

Results revealed that with the exception of the age of retirement and age at first registration as senior player all the KCI considered from the mastery stage influenced the competitive level of retirement of players. For example, regarding the first competitive level as senior player, the results revealed that $20 \%, 69.4 \%$, and $74.1 \%$ of the players who enter in mastery stage as a professional, elite, first pro and second procompetitive level, respectively, finish their career as non-professional players. Additionally, the transition from junior to senior is not only a critical moment to avoid dropout, ${ }^{1}$ but is also crucial for the development of the mastery stage of football players, with consequences in the competitive level of retirement. Hollings et al. ${ }^{36}$ pointed the initial senior success as one of the reasons for the athlete being successful in senior sport. In opposition to the frequent strategies adopted by football players, ${ }^{9}$ all the decisions regarding the first club as senior players, the existence of a dual career or even the definition of a lifetime career as professional should be accounted for the definition of the players' career path. Understanding the career as a process that could be planned and managed in opposition to a sum of positive or negative events that could occur due to external factors, allow the players to perceive the process of retirement as much less difficult. ${ }^{15,37}$

Similarly, the results revealed that for each additional season played in the mastery stage, a decrease in the chances to finish the career as professional player was observed. However, in the opposite view, the analysis of the total number of games played in the mastery stage revealed that for each additional game played, an increase in the chances to finish a career as a professional player was observed. Beyond that, an important issue to maintain the career in a high level is the participation in high number of games throughout the seasons. Therefore, the evolution of the number of games per season could be a key issue to manage the career and prospectively evaluate the possibilities for the future. Certainly, the conscience about the tendencies of selection or deselection ${ }^{28}$ during seasons are crucial to maintain the expectations for the future and prospectively evaluate the possibilities of a career as a continuous process. ${ }^{1,14}$

At the end, the results revealed that the age of the last best result achieved over the mastery stage influences the competitive level of retirement of players. Accordingly, the later the best result was achieved in mastery stage, the greater the chances to end the career as professional player. Based on previous research, it was observed that in the analysis of the lifespan of French elite male athletes ${ }^{38}$ the career termination was facilitated according to the athletes' achievements during their sports career. Feeling of self-achievements and career goals were revealed as a strong predictor of the quality of retirement of elite athletes. ${ }^{12}$ However, further research is required in order to link the level of achievements with the competitive level of retirement of players and the quality of retirement.

The current research presents some limitations due to the difficulty to identify the most reliable variables as predictors of the mastery stage of the athletic career. Further research is required on this topic in the future for the characterization of different stages of an athletic career in different countries. There is no doubt that the analysed KCI, particularly the trend in the number of 
games played over seasons, and the age of the last best result achieved influence and help to predict the last years of the career path of Portuguese football players. Thus, managers and players should use them for the future as predictors of sports career development, allowing to prepare the image of retirement, ${ }^{9}$ and voluntary termination decisions. In line with the case studies revealed, career management is a complex process with different pathways. There is no single way to achieve a successful career management. The KCI should be used to improve the consciousness of players and managers about career achievements, helping to prospectively prepare the moment of retirement.

\section{Conclusion}

The main purpose of the current study was to characterize the mastery stage of Portuguese football players and understand how the development of mastery stage of football players' career influences the competitive level of retirement. The results highlighted reliable variables for prospective analysis of athletic career of football players, allowing to improve a smooth career termination. Furthermore, the results demonstrated how Mastery stage influence the retirement level of football players. The relationship observed between the variables from mastery stage and the competitive level of retirement have important implications on the definition of management and support programs of players' careers.

\section{Acknowledgments}

The authors would like to thank to digital website platform www.zerozero.pt for the partnership on the development of this study.

\section{Declaration of conflicting interests}

The author(s) declared no potential conflicts of interest with respect to the research, authorship, and/or publication of this article.

\section{Funding}

The author(s) disclosed receipt of the following financial support for the research, authorship, and/or publication of this article: This work was supported by the National Funding through the Portuguese Foundation for Science and Technology, I.P., under the project UID04045/2020.

\section{ORCID iD}

Bruno Travassos (D) https://orcid.org/0000-0002-2165-2687

\section{References}

1. Stambulova N, Alfermann D, Statler T, et al. ISSP position stand: career development and transitions of athletes. Int J Sport Exerc Psychol 2009; 7: 395-412.

2. Knights S, Sherry $E$ and Ruddock-Hudson M. Investigating elite end-of-athletic-career transition: a systematic review. J Appl Sport Psychol 2016; 28: 291-308.

3. Park S, Lavallee D and Tod D. Athletes' career transition out of sport: a systematic review. Int Rev Sport Exerc Psychol 2013; 6: 22-53.

4. Ekengren J, Stambulova N, Johnson U, et al. Exploring career experiences of Swedish professional handball players: consolidating first-hand information into an empirical career model. Int J Sport Exerc Psychol 2018; 18: 156-175.

5. Carapinheira A, Mendes P, Carvalho PG, et al. Sports career termination in football players: a systematic review. Revista Iberoamericana de Psicología del Ejercicio y el Deporte 2019; 14: 61-65.

6. Bailey M. What do footballers do when they retire? The Telegraph 2014. [AQ3]

7. van Ramele S, Aoki H, Kerkhoffs GM, et al. Mental health in retired professional football players: 12-month incidence, adverse life events and support. Psychol Sport Exerc 2017; 28: 85-90.

8. Sanders G and Stevinson C. Associations between retirement reasons, chronic pain, athletic identity, and depressive symptoms among former professional footballers. Eur J Sport Sci 2017; 17: 1311-1318.

9. Carapinheira A, Torregrossa M, Mendes P, et al. A retrospective analysis of retirement of football players in Portugal. Motricidade 2019; 14: 75-85.

10. Torregrosa M, Ramis Y, Pallarés S, et al. Olympic athletes back to retirement: a qualitative longitudinal study. Psychol Sport Exerc 2015; 21: 50-56.

11. Dimoula F, Torregrosa M, Psychountaki M, et al. Retiring from elite sports in Greece and Spain. Spanish $J$ Psychol 2013; 16: E38.

12. Demulier V, Le Scanff C and Stephan Y. Psychological predictors of career planning among active elite athletes: an application of the social cognitive career theory. J Appl Sport Psychol 2013; 25: 341-353.

13. Martin LA, Fogarty GJ and Albion MJ. Changes in athletic identity and life satisfaction of elite athletes as a function of retirement status. J Appl Sport Psychol 2014; 26: 96-110.

14. Wylleman P, Alfermann D and Lavallee D. Career transitions in sport: European perspectives. Psychol Sport Exerc 2004; 5: 7-20.

15. Wylleman P, Reints A and De Knop P. A developmental and holistic perspective on athletic career development. In: Sotiriadou P and Bosscher VD (eds) Managing High Performance Sport. London: Routledge, 2013, pp.159-82.

16. Brown CJ, Webb TL, Robinson MA and Cotgreave R. Athletes' experiences of social support during their transition out of elite sport: an interpretive phenomenological analysis. Psychol Sport Exerc 2018; 36: 71-80.

17. Stambulova $\mathrm{N}$ and Ryba TV. A critical review of career research and assistance through the cultural lens: towards 
cultural praxis of athletes' careers. Int Rev Sport Exerc Psychol 2014; 7: 1-17.

18. Schroepf B and Lames M. Career patterns in German football youth national teams - a longitudinal study. Int J Sports Sci Coach 2018; 13: 405-414.

19. Carapinheira A, Mendes P, Guedes Carvalho P, et al. Career termination of Portuguese elite football players: comparison between the last three decades. Sports 2018; 6: 155

20. Ekengren J, Stambulova N, Johnson U, et al. Composite vignettes of Swedish male and female professional handball players' career paths. Sport Soc 2020; 23: 595-612.

21. Battochio RC, Stambulova N and Schinke RJ. Stages and demands in the careers of Canadian National Hockey League players. J Sports Sci 2016; 34: 278-288.

22. James N, Taylor J and Stanley S. Reliability procedures for categorical data in performance analysis. Int $J$ Perform Anal Sport 2007; 7: 1-11.

23. Fritz CO, Morris PE and Richler JJ. Effect size estimates: current use, calculations, and interpretation. J Exp Psychol: General 2012; 141: 2.

24. Cohen J. Statistical power analysis for the behavioral sciences. Abingdon: Routledge, 2013.

25. Kotrlik JW, Williams HA and Jabor MK. Reporting and interpreting effect size in quantitative agricultural education research. J Agricult Educ 2011; 52: 132-142.

26. Alfermann D and Stambulova N. Career transitions and career termination. In: Tenenbaum RC and Eklund $\mathrm{G}$ (eds) Handbook of sport psychology. 3rd ed. New York: Wiley, 2007, pp.712-733.

27. Moesch K. Reasons for career termination in Danish elite athletes: investigating gender differences and the time-point as potential correlates. Sport Sci Rev 2012; 21: 49-68.
28. Butt $\mathbf{J}$ and Molnar G. Involuntary career termination in sport: a case study of the process of structurally induced failure. Sport Soc 2009; 12: 240-57.

29. Stambulova N and Wylleman P. Athletes' career development and transitions. Routledge companion to sport and exercise psychology. Abingdon: Routledge, 2014, pp.629-644.

30. Agresta MC, Brandão MRF and Barros Neto TLD. Physical and emotional causes and consequences of career termination in sports. Revista Brasileira de Medicina do Esporte 2008; 14: 504-508.

31. Barreira J. Age of peak performance of elite women's soccer players. Int J Sports Sci 2016; 6: 121-124.

32. Dendir S. When do soccer players peak? A note. J Sports Analyt 2016; 2: 89-105.

33. Allen SV and Hopkins WG. Age of peak competitive performance of elite athletes: a systematic review. Sports Med 2015; 45: 1431-1441.

34. Rintaugu EG, Mwisukha A and Monyeki M. From grace to grass: Kenyan soccer players' career transition and experiences in retirement: sport participation. Afr $J$ Phys Activity Health Sci 2016; 22: 163-175.

35. Drawer S and Fuller C. Perceptions of retired professional soccer players about the provision of support services before and after retirement. Br J Sports Med 2002; 36: 33-38.

36. Hollings SC, Mallett CJ and Hume PA. The transition from elite junior track-and-field athlete to successful senior athlete: why some do, why others don't. Int $J$ Sports Sci Coach 2014; 9: 457-471.

37. Torregrosa M, Boixadós M, Valiente L and Cruz J. Elite athletes' image of retirement: the way to relocation in sport. Psychol Sport Exerc 2004; 5: 35-43.

38. Debois N, Ledon A and Wylleman P. A lifespan perspective on the dual career of elite male athletes. Psychol Sport Exerc 2015; 21: 15-26. 